\title{
Body Capital in Education in Brazil and the United States
}

\author{
Antonio José Müller, Fernanda Stedile \\ Universidade Regional de Blumenau, Blumenau, Brazil
}

\begin{abstract}
The example of body capital is given by the movement and sports that a particular culture enjoys or practice. The body is the center of physical education (PE) and sport, body capital is the capital that bodies have according to the cultural or economic importance that this body interacts in relation to its "use” for a particular sport or activity. In this context, groups of people admire the same body aesthetics, with a standardized biotype for a certain sport modality that is culturally appreciated and valued, which has also evidenced this body or embodied dimension of experience in a certain sport activity. This study aims to understand the condition and importance of the body related to education in Brazil and the United States (U.S.). The main objective is to compare the importance of the body in the education of these countries. Searching through bibliographic, the intention of this research is to understand how the body capital, movement, sports, and aesthetics, are related to the culture of each country. The research recognize how the body and its capital interfere in the education of the students and consequently in their academic and social development.
\end{abstract}

Keywords: body capital, education in Brazil, education in United States (U.S.), physical education (PE) and sport

\section{Introduction}

The history and anthropology of the body in society are involved in the very history of mankind. In classical Greek society, the perfect physical form of the athlete participating in the Olympics was reflected in the Greek concept of beauty ideal and essential component in the pursuit of human excellence. The emphasis on individual athletic achievement through public competition was related to the Greek ideal of physical, moral, and mental excellence, called "arête" (Spears \& Swanson, 1988). Greek society has made sport an important event and the fantasy of the search for the perfect body persists in society today.

Thus, there is a pattern of beauty in each culture and historical time. Ugliness is relative to the times and to cultures, what was unacceptable yesterday maybe acceptable tomorrow, and what is perceived as ugly may contribute, in suitable context, to the beauty of the whole (Eco, 2007) within a single culture, as well as economic power. According to Marx (2004), "I am not ugly, because the effect of ugliness, its power of repulsion, is annulled by money.” The standard of beauty defined today refers to a lean body (in the case of women) and muscular (in the case of men).

In Brazil, the body has great social and cultural impact and it is the object of study and debate in several areas of knowledge. In turn, because of its monopoly of investments, manipulating information and socio-cultural standards the media make the body great profits. In the United States (U.S.), the body as an expression of the American way of life also serves as a tool for educational purposes as scholarships for

Antonio José Müller, Dr., professor, Department of Physical Education, Universidade Regional de Blumenau. Fernanda Stedile, Bachelor student, Department of Physical Education, Universidade Regional de Blumenau. 
athletes, which guarantees the future of many high school youth. The aim that is an extremely undervalued field, where scholarships for athletes are almost nil in Brazil and the encouragement of education walks in the same way.

In this study, we can better understand what body capital represents in Brazilian and American culture and how it can open the door to an improved education that works for the sake of respect and self-knowledge. Physical education (PE) is the key to break away from major blockades that have been built for years in the social and cultural milieu.

The present study has the literature and bibliography as the main instrument of information collection, using the main authors on the subject in Brazil and the U.S., as well as descriptions or facts that related the capital subject of the body and school. Also, it is presented as a qualitative and comparative research, because it describes and interprets cultural behavior in different realities (Schwandt, 2001). The main objective of this study is as following:

1. To compare the importance of the body in the education of Brazil and the U.S.;

2. To understand how the capital of the body is related to the culture of each country;

3. To differentiate the context of the importance of the body related to movement, sports, and aesthetics in each culture;

4. To perceive how the body and its capital interfere in the education of the students and consequently in their academic and social development.

\section{Body Capital}

In Karl Marx's (2011) best-known book entitled Capital, he made an analysis of the relationship between the body and capitalist society from the discussion with the work in the dialectical materialist perspective and in the cultural industry. It presented a discussion about the role of work in the process of consolidation of the body aesthetics, and also debated about the role of the mode of production and some of its instruments in determining the body models that established the process of body education.

Among the scholars of the "modern body," Foucault (1987) identified the mechanisms of objectification of the body. He described the constitution of modern subjectivity as a gradual process of disciplining bodies through a political technology of the body and a microphysics of power that involved a set of techniques, processes, dispositions, and knowledge.

Cultural capital can exist in three forms, according to Bourdieu (1979):

In the embodied state, cultural capital can exist in the form of durable arrangements of the organism; In the objective state, it exists in the form of cultural goods-paintings, books, dictionaries, instruments, and machines, which are indications, theories, or critiques of such theories, problems, etc.; and finally, in the institutionalized state, it exists in a form of objectification that must be set aside, because as is seen in relation to the school certificate, it confers on cultural capital—which is supposedly the guarantee-entirely original properties. (p. 3)

Bourdieu (1986) completed the thought in relation to cultural capital and the property acquired and incorporated by the individual himself, which he called "the incarnate state." The incarnate state is related to the purpose of this research as the condition of the property of the capital of the body and its presence in the predominant culture, because:

Most of the properties of cultural capital can be deduced from the fact that, in its ground state, it is connected to the body and pre-supposes an incorporation, which implies a work of inculcation and assimilation. Time costs must be invested personally by the investor. Like the acquisition of a muscular physique or a tan, it cannot be done second-hand. 
Body capital is our individual, physical, and public connection, which provides a means of obtaining from the body (corpore) a form of consent that the mind (men) could refuse (Bourdie, 1986, as cited in Dunning, Murphy, \& Williams, 1993). The relations between bodily disciplines, habits, ceremonies, and power and their numerous manifestations in both pleasurable social forms and oppressive forms vary in societies. Bodily manifestations constitute and express the relative powers of classes, regions, racial, ethnic groups, and genders. This could only win legitimacy as a cultural project if it could be harmonized with new class needs for labor discipline, education, and the control of public order.

Bodies are the center of PE and sport. However, bodies are also a form of identity, are socially produced or constructed, and a site of social difference and division (Hayes \& Stidder, 2003). Usually, this involves a constant process of imitation by the lower-class of higher-class habits, and it is a re-production of higher-class power and privilege.

The dominant cultural features of this self-consciously modern form of sporting practice centered on two distinct concepts of discipline:

1. The notion of self-discipline through the exercise of a person's supposedly higher faculties of reason;

2. The disciplinary bodily mastery achieved through techniques that were synthesized into a new kind of culture to live life in a certain form.

In this way, the perfectly proportioned bodies of Greek male athletes, revealed in the paintings and sculptures became the idealized bodily aesthetic (Dunning, Murphy, \& Williams, 1993). In modern days, body is style and their characteristics define the position in society. Since each culture values specific physical characteristics, the perfection of bodies is less important than are the physical characteristics for a particular sport or activity in particular society.

Some of the capital that poor pupils have is their bodies. But not every pupil is talented or physically prepared to use his/her body capital in specific sport. The key point is that body capital limitations can reproduce class inequalities. During PE classes, teachers must prevent these limitations by addressing issues of social deprivation and disadvantage promoting social inclusion for all variety of bodies.

Body capital is also discriminatory where there is a strong downside as those controlling the images of the body. Media and corporation define what is normal and beautiful and making fortunes based on that control.

Body capital has many different definitions and applications. Society is a point that defines body capital. For instance, soccer in Brazil is a sport predominantly played by poor blacks/mulatos and male. In the U.S., soccer is predominantly played by middle-class white girls. Therefore, to be successful in a specific culture, body capital must follow what kinds of talents or skills are socially constructed. Let us use music to compare: U.S. population appreciates jazz and Brazilians appreciate samba because of the historical and cultural background. In sport, Brazilian society will recognize a talented player in soccer more than in American football because of the cultural importance of soccer in that country. Brazilian soccer player has unique corporal movement which follows the cultural appreciation of its population as the same in the U.S. for football players. If one football player tries to play soccer in Brazil, he probably will be in trouble in the "eyes" of Brazilians, because of the different style or movements which are important characteristics in American football rather than soccer.

Sport is a form of societal expression and each society has a sport or sports as a mirror (Melo, 2000). Therefore, the objective in this research is to understand body capital as physical expressions which are socially and culturally constructed in each country. 


\section{Body Capital in PE and Sports}

Historically, male Greek athletes and their bodies of perfect proportions, revealed in paintings and sculptures have become idealized body aesthetics (Dunning, Murphy, \& Williams, 1993). Nowadays, the style of the body and its characteristics define the position of society, since each culture values specific physical characteristics. Thus, the perfection of bodies is less important than are the physical characteristics for a given sport or activity in a given society.

Another example of body capital is given by the movement and sports that a particular culture enjoys or practice. The body is the center of PE and sport, and body capital is the capital that bodies have according to the cultural or economic importance that this body interacts in relation to its "use" for a particular sport or activity. The noble side is since sports participation provides a focus for social activity, an opportunity to make friends, develop networks, and reduces social isolation, it seems well placed to support the development of the body as individual or collective social capital.

Sport is a form of expression of society and each society has its sport or a sport as a mirror (Melo, 2000). The dominant cultural characteristics act in the self-conscious of sports practice centered on two distinct concepts of discipline:

1. The notion of self-discipline provided by exercise and effort, where supposedly the practitioner acquires a rational power of greater balance;

2. Body mastery achieved through the techniques that have been synthesized into a new type of culture required in a particular activity or to live life within modern fads.

We must be attentive in PE, because not every student is talented or physically prepared to use his/her body capital in the specific sport. Also, part of the capital that poor students have is their bodies. But not all students are talented or physically prepared to use their corporate capital in a specific sport.

The key point is that individual limitations of body capital can reproduce class inequalities. During PE classes, teachers should prevent these limitations by making it easier for each student to understand their body, their differences, and their specificities. It is very important to show and idealize respect for each body. In order to emphasize that each one owns his/her corporal capital, needing to take care of and respect him/her, as well as his/her similar.

The capital of the body has some negative dimensions. Two obvious factors can be addressed: Firstly, the capital of the body can be impermanent. Many athletes prematurely discontinued their careers due to injuries. In addition, sooner or later, all those who perform professional types should give up. The worst part is that they have no experience in different fields and are suffering to keep their lives at the same level they had with astronomical salaries. Unlike artists who may have a "longer working life,” many athletes were quickly failing in oblivion and depression. It is the dying of a life of glory, money, admiration and rebirth in a regular life and not everyone knows how to hold it. Secondly, schools use the capital of the body to generate capital. Athletes are used for exploration to raise money for schools or companies and/or to generate the school spirit literally on the bodies/backs of the athletes.

\section{The Representation of the Body in Brazilian Education}

As described, the capital of the body is related to aesthetics and cultural and social models in each region of the planet. For reasons of health, aesthetics of religion, human capital or economic factors, the body is the 
center of studies and practice in various cultures. In Brazil, there is a very strong relationship between body and aesthetics. According to Baptista (2013), a particular body model in contemporary Brazilian culture was a wealth, perhaps most desired by individuals in the urban middle-strata and also by the poorer strata, who perceived their body as an important vehicle for social ascension. Also, important capital in the labor market, in the marriage market, and in the sex market. In this sense, besides physical capital, the body is also a symbolic capital, an economic capital, and a social capital. For the author, in Brazil, however, it must be emphasized that this capital body is not a body whatsoever. For Brazilian culture, the body should always be sexy, skinny, young and in good shape. A conquering body through a huge financial investment, a lot of work, and a good dose of sacrifice (Baptista, 2013).

Still in Brazil, the capital of the body is represented by soccer players who have the ideal biotype for soccer, being this biotype by high performance, and in the combination of the common Brazilian biotype, which is closely related to the success within the sport more popular in the country.

In Brazilian education, how can the body be represented? According to Camargo (2005):

In infancy, the moving body constitutes the basic matrix in which the meanings of learning are developed, because the child transforms into symbol what he/she can experience bodily and his/her thought is first constructed in the form of action.

In this way, we can observe that the corporal representation begins from childhood, when the child should be encouraged to the movements to obtain learning. Thus, the relation of the body in movement makes great importance in the construction of the knowledge of an individual. In Brazil, PE is responsible for encouraging the movement since the early years, comes from a reputation for failures and unprofitable moments. In general, school practice can be seen as a practice based on "a mere doing to do". As the author put it, "a mere to do,” we come from a culture where that expression prevails in the body culture of school physical education. Roughly speaking, it would be possible to say that this factor implies a radical change in the learning and education of Brazilians.

In school education, body culture has an impact just as there is in the "adult" society, where there is a perfect physical type, as we discussed earlier. The body represents more than just movements and learning, the body represents a cultural, social, and meaningful element of its own. As Nobrega (2005, p. 608) said that, "The body is not merely an instrument of educational practices, human productions are possible, because we are body. The body being not only an instrument, but being as the body."

\section{Body Representation in American Education}

In the U.S., the body in education has different meanings to Brazil. With strong support for the sport, Americans use their body capitals to obtain scholarships at renowned universities. For Americans, the body is not only a reference to their appearance, but also a means of obtaining a promising future. The same country that uses its largest capital, the body, to get into a good university later ends up consuming thousands of empty calories and getting over-weight. What representation does this body have in a society where we can affirm if we find patterns of beauty that exalt a lean and slender body as opposed to the obese or over-weight body? (Larini \& Simões, 2009).

Those who do not fit this pattern of beauty suffer the consequences of contempt or oppression, as is the case of bullying in schools. The U.S. is a country known for its history of bullying, and several students miss 
school daily for fear of humiliation, beatings, or verbal abuse. We know that the body has a great impact on the educational, social, and cultural environment. Not having a body in the standards provides a great impact on the self-esteem of children and adolescents, as well as on the quality of their learning. This is negatively affected by factors that negatively imply teaching-learning of these students.

To understand the body as an existential subject, always living in the sense of self-improvement, being this body actor and author of its history and culture is corporeity, indenting the symbols and signs that have been tattooed throughout the ages (Moreira, 2003, as cited in Larini \& Simões, 2009).

The body brings social and historical marks, so cultural issues, gender issues, and social belongings can be read in the body (Nobrega, 2005, p. 608). The way we deal with the body, has great impact on our lives. Thus, the culture that exists in the U.S., the lifestyle, exerts impacting factors on the body representation of the American or the individual present in this social culture.

\section{The Relationship of the Body in Brazil and U.S.}

In the U.S., there is a different understanding of the relationship between body capital and education. Students, especially not high school, compete in interscholastic events and use their sports skills to pursue a scholarship for higher education. It established information on the impact of sport on the statistical correction between athletic participation and better educational performance (Sokol-Katz, Kelley, Basinger-Fleischman, \& Braddock, 2006). In this way, the capital of the body is better associated with an education than Brazil, where scholarships for athletes are almost nil.

We can also observe that the representation of the body in the U.S. has a bias that is totally out of control when we talk about obesity. Most of the American population suffers from this evil, the media play a large role with its advertisements and inducements to dubious food. The relation of corporal capital justifies the self-esteem of each individual, the one that is affected when we focus on this aspect. For the most part, it has been transformed into the socio-cultural phenomenon called bullying.

Body capital can be considered discriminatory, where there is a strong exploitation and over-valuation of those who control the images of the body, and thus, determine which body to be considered ideal and capital for a particular sport or culture. The media and society define what is normal and beautiful, making fortunes based on that control and on the bodies and their capital. We can apply this concept in different societies where concepts are also constructed differently. For example, in essence football in Brazil is a pre-dominantly masculine sport practiced by blacks or mulattoes of low- or middle- social class. On the other hand, soccer in the U.S. is predominantly practiced by white middle-class girls and women. Therefore, to be successful in a specific culture, body capital respects the kinds of talents and skills required in regional, cultural, historical, and social sports that are socially constructed.

In sport, Brazilian society will recognize a talented player in football is much more than in American because of the cultural importance of football in Brazil. The Brazilian football player has unique body movement, which follows the cultural appreciation of his/her population. The same happens in the U.S. for football players, he/she probably will not have the same attention to the "eyes" of the Brazilian public, due to the differences of movement and style that do not perceive football as an important sport in its historical and cultural reality. 


\section{Final Considerations}

Through the research, one can perceive how the body and its capital interfere in the education of the students and consequently in their academic and social development. The body in all its perspective revolves around being. Body capital is about body capital, which demonstrates the society, culture, and environment that the individual is inserted.

In each country, it was possible to identify and list different meanings for the capital of the body. For the representation of the American body, it was possible to identify some factors that influence its representativeness, such as bullying, scholarships for athletes, the media, and cultural factors. In Brazil, the factors related to the media are similar, but they differ when we speak of scholarships for athletes, which are almost non-existent for Brazilians. Cultural issues also strongly influence body representation in Brazil, in a milder way than in the U.S..

The key point is that body capital constraints can reproduce class inequalities. During PE classes, teachers should avoid these limitations by addressing issues of social deprivation and disadvantage by promoting social inclusion for all body types.

The body as capital is the representation of being not only as an instrument of learning, but as being body. In PE, body vision can be somewhat discriminatory, aiming that not every student will be good at finished sport. There is an overvaluation of those who have more talent. This valuation becomes impactful socio-culturally. We can observe at the time of this research, how the body can have diverse representations and each of them impact differently in the life of the individual.

Thus, the capital of the body must follow the kinds of talents or skills that are built in each culture with its distinct goals. It remains to be seen how people and their body capital can take advantage of this context for the benefit of quality education.

\section{References}

Baptista, T. J. R. (2013). An educação do corpo na sociedade do capital (The education of the body in the society of capital). Curitiba: Appris Editora.

Bourdieu, P. (1979). Les trois états du capital culturel (The three states of cultural capital). In Actes De La Recherche En Sciences Sociales (Proceedings of social science research) (pp. 3-6). Paris: Minuit Editors.

Bourdieu, P. (1986). The forms of capital. In J. Richardson (Ed.), Handbook of theory and research for the sociology of education (pp. 241-258). New York, N.Y.: Greenwood Publications.

Camargo, M. (2005). O corpo em movimento na Educação Infantil: Uma linguagem da criança (The body in motion in early childhood education: A child’s language). Curitiba: Universidade Federal do Paraná.

Dunning, E., Murphy, P., \& Williams, J. (1993). Spectator violence at football matches: Towards a sociological explanation. In N. Elias, \& E. Dunning (Eds.), Quest for excitement: Sport and leisure in the civilizing process (pp. 245-266). Cambridge: Blackwell.

Eco, U. (2007). História da feiúra (On ugliness). Rio de Janeiro: Record Editora.

Foucault, M. (1987). Vigiar e punir (Discipline and punish). Petrópolis: Vozes Editora.

Hayes, S., \& Stidder, G. (2003). Equity and inclusion in physical education and sport. London: Routledge.

Larini, K. C. P., \& Simões, R. (2009). Sobrepeso ou obesidade: A visão de corpo de mulheres maduras (Overweight or obesity: The body vision of mature women). Movimento \& Percepção, 10(14), 1679-1678.

Marx, K. (2004). Manuscritos econômico-filosóficos (Economic and philosophical manuscripts). São Paulo: Martin Claret.

Marx, K. (2011). O capital: Crítica da economia política (Capital: Critique of political economy) (Vol 1, 29a ed.). Rio de Janeiro: Civilização Brasileira.

Melo, V. A. (2000). Futebol que história é essa? (Football what history is it?) In P. Carrano (Ed.), Futebol: Paixão e política (Football: Passion and politics). Rio de Janeiro: DP \& A Editora. 
Nobrega, P. T. (2005). Qual o lugar do corpo na educação? Notas sobre conhecimento, processos cognitivos e currículo (What is the place of the body in education? Notes on knowledge, cognitive processes, and curriculum). Educ. Soc., Campinas, 26(9), 599-615.

Schwandt, T. A. (2001). Dictionary of qualitative inquiry. Thousand Oaks, C.A.: Sage Publications.

Sokol-Katz, J., Kelley, M. S., Basinger-Fleischman, L., \& Braddock, J. H. (2006). Re-examining the relationship between inter-scholastic sport participation and delinquency: Type of sport matters. Sociological Focus, 39(3), 173-192.

Spears, B., \& Swanson, R. (1988). History of sport and physical education in the United States. Dubuque, Iowa: Wm. C. Brown Publishers. 